\title{
Kernos
}

Revue internationale et pluridisciplinaire de religion grecque antique

6 | 1993

Varia

\section{J. Leclant, G. Clerc, Inventaire bibliographique des Isiaca (IBIS)}

Michel Malaise

\section{(2) OpenEdition \\ Journals}

Édition électronique

URL : http://journals.openedition.org/kernos/570

DOI : $10.4000 /$ kernos. 570

ISSN : 2034-7871

Éditeur

Centre international d'étude de la religion grecque antique

Édition imprimée

Date de publication : 1 janvier 1993

Pagination : 389-391

ISSN : 0776-3824

Référence électronique

Michel Malaise, « J. Leclant, G. Clerc, Inventaire bibliographique des Isiaca (IBIS) », Kernos [En ligne], 6।

1993, mis en ligne le 07 avril 2011, consulté le 21 septembre 2020. URL : http:// journals.openedition.org/kernos/570 ; DOI : https://doi.org/10.4000/kernos.570 
Claude CALAME signe également une étude : Espaces liminaux et voix discursives dans l'Idylle I de Théocrite : une civilisation de poète. Il y revient sur l'un des poèmes les plus étudiés de Théocrite, en analysant la structure du texte, l'enchevètrement des différentes voix du poème (protagonistes, narrations, descriptions) et les espaces impliqués par chaque discours, l'œuvre se ramenant à une fiction poétique qui «insère en milieu urbain le domaine intermédiaire des pasteurs musiciens».

Pour Anne Julia VOILLAT SAUER (Entre exotisme et héroïsme : les Celtes de Posidonios), l'ethnographe stoïcien, en décrivant minutieusement les mœurs des Celtes de Gaule, ne les situe pas radicalement dans la barbarité (malgré plusieurs coutumes inacceptables pour un Grec); certains aspects de leur mode de vie sont assimilés à des mours typiquement grecques (celles des héros homériques); d'autre part, la sujétion des Celtes à leurs sages est propre à intéresser un stoïcien, pour qui l'humanité est unique et fondée sur la possession du logos.

Enfin, en synthétisant les références aux poèmes homériques apparaissant dans l'Histoire vraie de Lucien, Danielle VAN MALMAEDER tend à montrer que le théoricien de l'historiographie s'attaque uniquement, par son pastiche, aux récits imaginaires produits par ces contemporains; l'œuvre d'Homère n'est pas strictement assimilable aux ouvres de fiction que Lucien critique : elle reste pour lui le modèle idéal qu'il lui plaît d'imiter lorsqu'il se livre lui-même à la fantaisie.

Gérald PURNELLE (Liège)

\section{J. LECLANT, G. CLERC, Inventaire bibliographique des Isiaca (IBIS). Répertoire analytique des travaux relatifs à la diffusion des cultes isiaques 1940-1969, R-Z, Leyde, New York, Copenhague, Cologne, E.J. Brill, 1991, 1 vol. in- $8^{\circ}$, IX +374 p. (Études préliminaires aux religions orientales dans l'Empire romain, 18).}

En 1971, le professeur J. Leclant, avec la colaboration de Gisèle Clerc, mettait en route une bibliographie analytique de tous les ouvrages et articles relatifs aux isiaca et aux aegyptiaca parus entre 1940 et 1969. Cette vaste entreprise qui englobe tout l'espace méditerranéen, et souvent bien au-delà, s'est révélée tâche fort lourde, car les recherches en cette matière se sont fortement multipliées à partir de 1955. Aujourd'hui les auteurs nous présentent le quatrième et dernier volume de leur Répertoire, désormais riche de 1752 titres et de 405 pages d'index, une véritable somme bibliographique appelée à rendre les plus grands services à tous ceux qu'intéresse la diffusion des dieux et des objets égyptiens ou égyptisants dans le monde antique. 
Le système de présentation utilisé est simple : chaque étude, classée dans l'ordre alphabétique des auteurs et dotée d'un numéro d'ordre, est suivie d'un résumé, souvent très circonstancié, qui permet de voir en quoi cette publication peut être utile. L'élaboration d'un index général d'une extraordinaire richesse à la fin de chaque volume facilitera beaucoup les recherches quand on voudra rassembler les références sur un sujet ou un point donné. On ne peut que remercier les auteurs de nous avoir offert un instrument de travail aussi précieux. On ose espérer que ce Répertoire connaîtra une suite pour les années postérieures à 1969. On soulignera cependant que si les volumes publiés ne dépassent pas 1969, les résumés proposent souvent, dès à présent, des références bibliographiques postérieures à cette date, de sorte que le Répertoire est en fait plus riche encore que ne le laisse supposer son titre.

Pour terminer, nous suggérons quelques titres qui auraient pu trouver place dans ce quatrième volume :

R. REBUFFAT, Hélène en Égypte et le Romain égaré (Hérodote II, 115 et Polybe, III, 22-24), dans Revue des Études Anciennes, 68 (1966), p. 245-263 (sur le récit hérodotéen, pour l'essentiel de source phénicienne, des aventures d'Alexandre et d'Hélène en Égypte).

E. RIEFSTHAL, Nemesis and the Wheel of Fate, dans Bull. The Brooklyn Museum, 17 (1956), p. 1-7 (étude sur le griffon et sur une stèle funéraire du IIe s. ap. J.-C. représentant un garçon romain flanqué du chien Anubis et du faucon Horus, et accompagné d'un griffon).

G. RONCHI, Pterophoras (Diodoro Siculo, I, 87, 8), dans La Parola del Passato, 121 (1968), p. 290-295 (sur le ptérophore du clergé isiaque).

M. SORDI, Le monete di Marco Aurelio con Mercurio e la "Pioggia miracolosa", dans Annali dell'Istituto Italiano di Numismatica, 56 (1958-59), p. 41-55 (la présence de Mercure sur les monnaies de Marc-Aurèle n'aurait pas de lien avec l'épisode de la pluie miraculeuse; l'empereur vouait un culte à Hermès Logios et Trismegistos, et non à Hermès Aerios, équivalent de Thot-Chou).

G. SOTGIU, Culti e divinità nella Sardegna romana attraverso le iscrizioni, dans Studi Sardi, 12-13 (1952-54), p. 575-588 (e.a. question d'Isis).

W. SPEYER, Religiöse Pseudepigraphie und literarische Fälschung im Altertum, dans Jahrbuch für Antike und Christentum, 8-9 (1965-66), p. 88-125 (question de Thot tenu pour l'inventeur de l'écriture à l'époque hellénistique p. 91-92).

J. TONDRIAU, Dionysos, Dieu royal : Du Bacchos tauromorphe primitif aux souverains hellénistiques Neoi Dionysoi, dans Annuaire De l'Institut de Philologie et d'Histoire Orientales et Slaves, 12 (1952), 
p. 441-466 (sur le culte de Dionysos zoomorphe et sur les diadoques, e.a. les Lagides, qui ont adopté dans leur iconographie ses cornes et posé au dieu réincarné, au Neos Dionysos).

H. WREDE, Ägyptische Lichtbräuche bei Geburten. Zur Deutung der Froschlampen, dans Jahrbuch für Antike und Christentum, 11-12 (1968-69), p. 89-93 (sur les lampes avec représentations d'une grenouille ou de Bès.

Michel MALAISE (Liège)

\section{Actes de colloques}

Jaime ALVAR, Carmen BLÁNQUEz, Carlos G. WAGNER (éds), Héroes, Semidioses y Daimones. Primer Encuentro-Coloquio de ARYS. Jarandilla de la Vera, Diciembre 1989, Madrid, 1992.

Ana I RIARTE, Elogio de Sirenas: el espejismo del héroe, p. 1-10

Raquel LÓPEZ MELERo, La serpiente guardiana en la antigua Grecia: mito y realidad, p. 11-31

Adolfo J. Domínguez Monedero, El héroe de Temesa, p. 33-50

Domingo PLÁcIDO, El héroe épico en la escena trágica de la ciudad démocrática, p. 51-58

Francisco DíEz DE VELASCo, Aportación al estudio del imaginario ático del paso al más allá: el genio psicopompo raptor del lécito Louvre CA 1264, p. 59-67

Miguel Ángel Elvira, Las personificaciones del paisaje en la poesía helenística, p. 69-79

Ana María VÁsquez Hoyos, La serpiente en la antigüedad: igenio o demonio?, p. 81-134

María José HIDALGo DE VEGA, Los oráculos y los sueños-visiones como vehículos de salvación en las novelas greco-romanas, p. 175-204

Inmaculada Fernández López y Luis Prieto Fernández, Démones $y$ sueños , p. 205-213

J. Manuel CoRÉs Copete, La monarquía y Hércules: un himno del s. II D.C., p. 215-221

Patricio GUINEA Díaz, La mitología al servicio de la ciudad: la ninfa Nicea, p. 223-230

Fernando G AScó, Devociones demónicas (s. II y III D.C.), p. 231-243

Jaime Alvar, Isis y Osiris Daimones (Plut. De Iside, 360 D), p. 245-263

Amando Jesús de Miguel Zabala, Demonología en Apuleyo, p. 265-272

Jesús SAN BERnardino, El DAIMON de Apolonio de Tiana según Filóstrato, p. 273-281

José Manuel Luque, Las entidades sabreanaturales menores en Celso: su demonología, p. 283-290 